\title{
Random regression model of growth during the first three months of age in Spanish Merino sheep ${ }^{1,2}$
}

\author{
A. Molina, ${ }^{* 3}$ A. Menéndez-Buxadera, $\dagger$ M. Valera, $\$$ and J. M. Serradilla $§$ \\ *Department of Genetics, University Campus of Rabanales, University of Córdoba. Carretera Madrid- \\ Córdoba Km. 396-a, CP 14071, Córdoba, Spain; †Institute National de la Recherche Agronomique (INRA), \\ Unité de Recherches Zootechniques, Guadeloupe, French West Indies; $¥$ Department of Agroforest Sciences, \\ EUITA, University of Seville, Seville, Spain; and §Department of Animal Production, \\ University Campus of Rabanales, University of Córdoba, Córdoba, Spain
}

\begin{abstract}
A total of 88,727 individual BW records of Spanish Merino lambs, obtained from 30,214 animals between 2 and $92 \mathrm{~d}$ of age, were analyzed using a random regression model (RRM). These animals were progeny of 546 rams and 15,586 ewes raised in 30 flocks, between 1992 and 2002, with a total of 45,941 animals in the pedigree. The contemporary groups (animals of the same flock, year, and season, with 452 levels), the lambing number (11 levels), the combination sex of lambs with type of litter (4 levels), and a fixed regression coefficient of age on BW were included as fixed effects. A total of 7 RRM were compared, and the best fit was obtained for a model of order 3 for the direct and maternal genetic effects and for the individual permanent environmental effect. For the maternal permanent environmental effect the best model had an order 2 . The
\end{abstract}

residual variance was assumed to be heterogeneous with 10 age classes; the covariance between both genetic effects was included. According to the results of the selected RRM, the heritability for both genetic effects $\left(h_{a}^{2}\right.$ and $\left.h_{m}^{2}\right)$ increased with age, with estimates of 0.123 to 0.186 for $h_{a}^{2}$ and of 0.059 to 0.108 for $h_{m}^{2}$. The correlations between direct and genetic maternal effects were -0.619 to -0.387 during the first $45 \mathrm{~d}$ of age and decreased as age increased, until reaching values from -0.366 to -0.275 between 45 to $75 \mathrm{~d}$ of age. Important changes in ranking of the animals were found based on the breeding value estimation with the current method and with the random regression procedure. The use of RRM to analyze the genetic trajectory of growth in this population of Merino sheep is highly recommended.

Key words: genetic parameter, growth, Merino sheep, random regression model

@2007 American Society of Animal Science. All rights reserved.

J. Anim. Sci. 2007. 85:2830-2839

doi:10.2527/jas.2006-647

\section{INTRODUCTION}

Recent results have been published on the use of random regression to analyze sheep growth under experimental (Lewis and Brotherstone, 2002) and commercial conditions (Fischer et al., 2004). Both studies show that there is important genetic variation not only for weights at different ages, but also for the shape of the growth

\footnotetext{
${ }^{1}$ This research was funded by the National Spanish Merino Association and by the General Assistant Management for Cattle Breeding Production Resources; General Cattle Breeding Management (Ministry of Agriculture and Fisheries).

${ }^{2}$ The authors wish to thank A. R. Gilmour (NSW Department of Primary Industries, Orange, Australia) for providing the ASREML program.

${ }^{3}$ Corresponding author: ge1moala@uco.es

Received September 21, 2006.

Accepted June 11, 2007.
}

curve. However, when analyzing preweaning growth in mammals, not only direct genetic effects $(a)$ should be considered but also the maternal effect $(m)$ and their correlation $\left(r_{a m}\right)$ with the direct effects. This correlation was not considered in the above-mentioned studies.

Much attention has been paid to problems linked to the estimation of direct and maternal genetic effects (and their covariance) using linear mixed models. The paper by Meyer (1997) shows a general statistical strategy to model and estimate the genetic parameters of both effects, whereas Safari and Fogarty (2003) reviewed the results available on different growth traits in sheep. Merino is one of the main branches of sheep breeds in the world. It derives from the Spanish Merino sheep and includes the largest census number with 220 million animals. In Spain it is farmed in the very difficult environmental conditions of the Mediterranean regions, where the breed plays an important economic, social and ecological role. In general, the animals are slaughtered 
Table 1. Average values of several indicators of growth for Spanish Merino lambs

\begin{tabular}{lcrrr}
\hline \hline Item & Valid No. ${ }^{1}$ & Mean $\pm \mathrm{SE}^{2}$ & Range & CV, \% \\
\hline Birth weight & 30,214 & $4.18 \pm 0.01$ & 1.3 to 6.3 & 20.9 \\
Body weight at the first visit ${ }^{3}$ & 30,214 & $11.39 \pm 0.02$ & 3.0 to 19.8 & 28.3 \\
Age at the first visit & 30,214 & $30.0 \pm 0.05$ & 1 to 45 & 27.4 \\
Weight at the second visit & 30,197 & $16.26 \pm 0.02$ & 7.6 to 26.0 & 24.8 \\
Age at the second visit & 29,895 & $49.3 \pm 0.05$ & 29 to 68 & 18.0 \\
Body weight at the third visit & 29,355 & $20.90 \pm 0.03$ & 10.4 to 32.0 & 22.0 \\
Age at the third visit & 29,355 & $65.8 \pm 0.06$ & 46 to 92 & 15.4 \\
Body weight at 30 d & 30,197 & $11.42 \pm 0.01$ & 6.07 to 17.90 & 21.9 \\
Body weight at 60 d & 29,895 & $19.23 \pm 0.02$ & 9.96 to 29.17 & 21.1 \\
Body weight at 75 d & 29,355 & $23.12 \pm 0.03$ & 12.01 to 34.96 & 20.8 \\
ADG birth to 30 d & 30,197 & $0.241 \pm 0.01$ & -0.044 to 0.457 & 31.7 \\
ADG 30 to 60 d & 29,895 & $0.260 \pm 0.01$ & 0.007 to 0.429 & 27.4 \\
ADG 60 to 75 d & 29,355 & $0.259 \pm 0.01$ & -0.028 to 0.433 & 26.0 \\
\hline \multicolumn{4}{r}{ Animals used for the analysis (definitive database). } \\
2Body weights are expressed in kilograms, and ages are expressed in days. \\
Bndividual lamb BW records were taken at 3 visits to each flock made by officers from the Spanish Merino \\
Breeders Association.
\end{tabular}

at a young age (less than $3 \mathrm{mo}$ ) in order to satisfy the strong market demands focused on the weight and age at slaughter and the seasonal pasture availability. Accordingly, the breeding program must consider the possibility to provide the genetic potential of the animals at different points of the age trajectory during the first 3 mo of age.

The objective of this study was to estimate the genetic parameters for BW of the Spanish Merino sheep during the first $3 \mathrm{mo}$ of age (from birth to slaughter), using random regression models including direct and maternal genetic effects and their correlation.

\section{MATERIALS AND METHODS}

Animal Care and Use Committee approval was not obtained for this study because the data were obtained from an existing database (Spanish Merino Breeders Association), and we did not experiment with live animals.

\section{Data}

The data used originally included 124,586 records of BW obtained from 32,701 lambs born in 43 flocks associated with the Spanish Merino Breeders Association (SMBA) from 1992 to 2002. Flocks with less than 150 records, values out of the range defined by the mean \pm 3.5 SD within a given age class (9 classes from 2 to 92 $\mathrm{d}$ of age, sequentially formed, with $10 \mathrm{~d}$ of difference in each class) and animals with an unregistered paternity were excluded. This represented a data set (FINAL) with $118,941 \mathrm{BW}$ records taken during the first $92 \mathrm{~d}$ age in 30 flocks, from 30,214 animals from 546 rams and 15,586 ewes (90\% with 2 or more progeny records). The pedigree of each animal was obtained from the official herd book of the breed, with 45,941 animals in total. The structure of these data sets showed that $50.3 \%$ of the sires of the lambs were sires of the ewes also and $57 \%$ of the animals with records were progeny of these common sires. At the same time, 1,061 females with records were also represented as ewes of 2,373 progeny with data.

According to the official procedure, individual BW records are taken at 3 visits to each flock by officers from SMBA. Table 1 shows some general descriptive information about this data set. Body weights at standard ages of 30,60, and $75 \mathrm{~d}$, and ADG estimated by interpolation by the official procedure of SMBA are included in this table. The breeders recorded birth weights but they were not used for this study. A group of rams were tested each year, and each one was mated to 40 randomly selected ewes, in a separate paddock for $40 \mathrm{~d}$, to control paternity of the lambs born. A longitudinal data set (FINALRR) with 88,727 records was constructed with the repeated records of the same animals contained in FINAL (the only difference was that the individual birth weight was not included).

\section{Statistical Procedure}

Different linear models were applied to the FINAL data set to provide a general description of the growth curve of the population of Spanish Merino sheep and to identify the main source of variation to be included in the genetic analyses.

For the genetic analysis, the following basic random regression model (RRM) was used for the FINALRR data set:

$$
\begin{gathered}
y=X b+\sum_{k=0}^{k_{a}-1} Z_{k} a_{k}+\sum_{k=0}^{k_{m^{-1}}} Z_{m} m_{k} \\
+\sum_{k=0}^{k_{p}-1} Z_{p} p_{k}+\sum_{k=0}^{k_{w}-1} Z_{w} w_{k}=\varepsilon_{r},
\end{gathered}
$$

where $y=$ a vector of BW of lamb ith at age $j ; b=\mathrm{a}$ vector of fixed effects of contemporary groups (CG is a combination of flock, lambing year and season with 452 
Table 2. Order of fit for the polynomial used in the different models, number of parameters (p), and information criterion

\begin{tabular}{|c|c|c|c|c|c|c|c|c|c|c|}
\hline \multirow[b]{2}{*}{ Model $^{1}$} & \multicolumn{3}{|c|}{ Genetic } & \multicolumn{3}{|c|}{ Environmental } & \multirow[b]{2}{*}{$\mathrm{p}^{4}$} & \multicolumn{3}{|c|}{ Information criterion $^{2}$} \\
\hline & Direct & Maternal & $\operatorname{Cov}^{3}$ & Individual & Maternal & Residual & & $\log \mathrm{L}$ & $\mathrm{AIC}$ & BIC \\
\hline $\mathrm{N} 2222 \mathrm{~A}$ & 2 & 2 & No & 2 & 2 & 1 & 12 & $-2,888$ & 5,798 & 5,901 \\
\hline $\mathrm{N} 2222 \mathrm{~B}$ & 2 & 2 & No & 2 & 2 & 10 & 21 & $-2,238$ & 4,518 & 4,715 \\
\hline N3322A & 3 & 3 & No & 2 & 2 & 1 & 18 & $-1,631$ & 3,296 & 3,455 \\
\hline N3322B & 3 & 3 & No & 2 & 2 & 10 & 27 & $-1,221$ & 2,496 & 2,749 \\
\hline Y2222B & 2 & 2 & Yes & 2 & 2 & 10 & 25 & $-2,198$ & 4,446 & 4,681 \\
\hline Y3322B & 3 & 3 & Yes & 2 & 2 & 10 & 36 & $-1,112$ & 2,278 & 2,531 \\
\hline Y3332B & 3 & 3 & Yes & 3 & 2 & 10 & 39 & -948 & 1,974 & 2,339 \\
\hline
\end{tabular}

\footnotetext{
${ }^{1}$ Under the model column, the number specifies the order of fit for the polynomial used; for instance, N2222A means a model of order 2 for genetic direct and maternal effects, individual permanent, and maternal environment, respectively. The letter A means homogeneous residual variance, and the letter B is for heterogeneous residual variance. $\mathrm{N}$ means that covariance between genetic direct and maternal effects was not considered and letter $\mathrm{Y}$ is the opposite.

${ }^{2}$ The greater is the value for logL or lower is the value of Akaike information criterion (AIC) and Bayesian information criterion (BIC), the better is the adjustment. The value of $\log \mathrm{L}$ is expressed as a difference from a base of $-760,000$.

${ }^{3} \mathrm{Cov}=$ covariance between genetic direct and maternal effects.

${ }^{4} \mathrm{p}=$ number of parameters in the model.
}

levels), parity number of the mother (11 levels), and a combination of lamb sex and litter size (4 levels), and with a fixed regression of order $\mathrm{k}=3$ within $\mathrm{CG}$ included; $a_{k}$ and $m_{k}=$ sets of $\mathrm{n}$ values ( $\mathrm{n}=$ number of animals) of $k$ random regression coefficients, corresponding to direct additive $(a)$ and maternal $(m)$ effects, with order of fit $k_{a}$ and $k_{m}$, respectively; $p_{k}$ and $w_{k}=$ sets of random effects with dimensions $I_{n}$ and $I_{w}$ ( $w=$ number of mothers) for permanent individual environment effects $(p)$ and maternal permanent environment effects $(w)$, for which the order of fit for the $k$ random regression coefficients fitted for these effects were $k_{p}$ and $k_{w}$, respectively; $Z_{a}$, $Z_{m}, Z_{p}$ and $Z_{w}=$ incidence matrices with dimensions $n$ $\times k_{a}$ for $Z_{a}$ and $n \times k_{m}$ for $Z_{m}, n \times k_{p}$ for $Z_{p}$, and $w \times k_{w}$ for $Z_{w}$, and where elements of these matrices are $Z_{i}=$ $\Phi_{i}=\forall_{i}\left(t_{i j}^{*}\right)$, for which $\forall_{i}$ are coefficients of selected Legendre polynomial, and $t_{i j}^{*}$ are ages standardized between -1 and +1 to use orthogonal polynomials $\left(\Phi_{i}\right)$ of $k_{i}$ order; and $\left(\varepsilon_{r}=\right.$ random residual heterocedastic effects for 10 age classes considered (first class for ages between 2 and $14 \mathrm{~d}$ and the others for consecutive weeks of age, except the last one that covered the last $2 \mathrm{wk}$ ).

A total of 7 models were compared and Table 2 shows the effects included in each RRM, the order of fit of polynomials together with the Log $L$ value and the model evaluation criteria. The numbers in the model column in this table represent the order of fit for the effects considered: direct genetic, maternal genetic, individual permanent environment $(P i)$, and maternal environment $(P m)$ respectively. The best model was selected using the likelihood ratio test, contrasting differences between 2 models with a $\chi^{2}$ distribution at $\alpha=5 \%$. However, there are no formal procedures for the selection of the best model when the numbers of parameters are not the same. According to recommendations of Foulley and Robert-Granié (2002), the Akaike information criterion (AIC) and the Bayesian information criterion (BIC) can be useful as guides because they adjust for number of parameters and sample size.

Mixed model equations for the effects included in these models are

$$
\begin{gathered}
{\left[\begin{array}{ccccc}
X^{\prime} X & X^{\prime} Z_{a} & X^{\prime} Z_{m} & X^{\prime} Z_{p} & X^{\prime} Z_{w} \\
Z_{a}^{\prime} X & Z_{a}^{\prime} Z_{a}+A^{-1} \otimes K_{a}^{-1} & Z_{a}^{\prime} Z_{m}+A^{-1} \otimes K_{a m}^{-1} & Z_{a}^{\prime} Z_{p} & Z_{a} Z_{w} \\
Z_{m}^{\prime} X & Z_{m}^{\prime} Z_{a}+A^{-1} \otimes K_{m a}^{-1} & Z_{m}^{\prime} Z_{m}+A^{-1} \otimes K_{m}^{-1} & Z_{m}^{\prime} Z_{p} & Z_{m}^{\prime} Z_{w} \\
Z_{p}^{\prime} X & Z_{p}^{\prime} Z_{a} & Z_{p}^{\prime} Z_{m} & Z_{p}^{\prime} Z_{p}+I_{p} \otimes K_{p}^{-1} & Z_{p}^{\prime} Z_{w} \\
Z_{w}^{\prime} X & Z_{w}^{\prime} Z_{a} & Z_{u}^{\prime} Z_{m} & Z_{w}^{\prime} Z_{p} & Z_{w}^{\prime} Z_{w}+I_{w} \otimes K_{w}^{-1}
\end{array}\right]} \\
{\left[\begin{array}{c}
b \\
a \\
m \\
p \\
w
\end{array}\right]=\left[\begin{array}{c}
X^{\prime} y \\
Z_{a}^{\prime} y \\
Z_{m}^{\prime} y \\
Z_{p y}^{\prime} y \\
Z_{w}^{\prime} y
\end{array}\right],}
\end{gathered}
$$

where $A$ is the numerator relationship matrix, $\otimes$ is the symbol for Kronecker's product, and $K_{i}$ is the (co)variance matrix of the random regression coefficients of the effects indicated by subscript. According to Kirkpatrick et al. (1990) the genetic regression coefficients matrix could be used to estimate the eigenvalues $\left(\lambda_{i}\right)$ and their associated eigenvectors.

The statistical analysis was implemented with the ASREML software developed by Gilmour et al. (2000). This software finds solutions for all variance components and the effects included in the model previously described. Following the proposal of Jamrozik and Schaeffer (1997), the genetic variance at a given age is estimated by the general expression

$$
\sigma_{x_{j}}^{2}=\Phi_{x_{j}} K_{x} \Phi_{x_{j}}^{\prime}
$$

where the subscript $x$ can be substituted for the estimation of variances of direct $\left(\sigma_{a_{j}}^{2}\right)$ and maternal $\left(\sigma_{m_{j}}^{2}\right)$ genetic 
effects and for individual $\left(\sigma_{p_{j}}^{2}\right)$ and maternal $\left(\sigma_{w_{j}}^{2}\right)$ permanent environmental effects, for BW $\left(L W_{j}\right)$ at $j$ age. When age $i=j$ the results give the variance at certain age, but for $i \neq j$ the results are the genetic covariance for $L W_{j}$ at different ages. The covariance between direct and genetic maternal effects at any pair of ages was estimated by the same principle using the corresponding genetic components. Heritability can be derived at any point in the trajectory, as well as the genetic correlations between 2 points by classical methods.

Solutions for the $k_{i}$ random regression coefficients for each animal can be used to estimate breeding values (BV) for any point in the age curve between 2 and $92 \mathrm{~d}$. For example, BV for the animal $i$ at $75 \mathrm{~d}$ of age will be:

$$
B V_{i, 75}=\sum_{\mathrm{k}=0} \Phi_{75} \mathrm{a}_{\mathrm{i}}^{\prime}
$$

where $a_{i}=\left[a l p h a_{i}\right.$ beta $_{i} L$ beta $\left.a_{i} Q\right]$ represents solution for animal $i$, with an intercept $\left(a l p h a_{i}\right)$ or mean genetic level for direct or maternal effect and the random regression coefficients of order $k_{i}=2$ (alpha betaL beta $Q$ - intercept, lineal, and quadratic coefficients), and $\Phi_{75}$ are the coefficients of the Legendre polynomial corresponding to 75 $\mathrm{d}$ of age. To generalize our results and apply this procedure, the BV for each animal was predicted and compared with the official method used by SMBA (a model with the same fixed and random effects as the basic RRM model used in this study) to BV estimation by BLUP procedures for BW adjusted previously at the fixed age of $75 \mathrm{~d}$.

\section{RESULTS}

Some basic statistics relating to growth characteristics of Spanish Merino lambs were presented in Table 1.

\section{Growth Curve Characteristics for Merino Lambs}

Figure 1 shows growth curve characteristics for Merino lambs. Each point represents the least square mean of BW estimated at the corresponding age with a GLM, which included the same fixed effects as those presented in the basic RRM described previously in material and methods. Despite the apparent linear growth, a polynomial equation of fourth order provided the best fit this growth curve. A previous study with the same data set showed that this growth curve has 3 different steps (Menéndez Buxadera et al., 2003a) and they were applied herein. In each of these steps, the LW is a linear function of age. In the first $14 \mathrm{~d}$ after birth there was a maximum daily growth rate $\left(b_{1}=0.291 \pm 0.022\right)$, later on, the growth rate decreased until $35 \mathrm{~d}$ of age $\left(\mathrm{b}_{2}=\right.$ $0.200 \pm 0.006)$. Finally, the growth rate rose until $75 \mathrm{~d}$ of age $\left(b_{3}=0.253 \pm 0.001\right)$ with a subsequent erratic growth pattern. As in the results presented by Menéndez-Buxadera et al. (2003a), the sex and number of lambs born were significant factors affecting the growth curve.

\section{Comparison of Random Regression Models}

The covariance between genetic direct and maternal effects was not considered in the first 4 models in Table 2 (marked with letter $\mathrm{N}$ ). The results of $\log \mathrm{L}, \mathrm{AIC}$, and BIC show a significant improvement in the level of fit when the heterogeneous residual variance (letter B) was included in the model, in comparison to homogeneous residual variance (letter $\mathrm{A}$ ). At the same time the use of order $\mathrm{k}=3$ for the polynomial in genetic direct and maternal effects dramatically increases the fit of the model, which will become clearer compared with models N3322A and N3322B with N2222A or N2222B.

The last 3 models in Table 2 included the heterogeneous residual variance and the covariance between genetic direct and maternal effects (letter Y). The importance of the covariance between both genetic effects was evident comparing the results from the first 4 models. Using a quadratic equation (order of fit, $\mathrm{k}=3$ ) for both genetic effects and for $P i$ and a linear equation $(\mathrm{k}=2)$ for $P m$ improved the fit and the model Y3332B with 39 parameters (Table 2), was selected as the best fitted to the data distribution according to the information criteria used (logL, AIC, and BIC).

\section{Eigenvalues and Variance Components}

Table 3 shows the random regression coefficient matrices for direct genetic and maternal effects and their covariance in model Y3332B. It is worth noting the negative covariance between coefficients of direct and maternal effects and the different patterns of correlations between coefficients of both effects. Correlations between intercept and linear and quadratic coefficients for direct genetic effects were 0.863 and 0.293 , respectively; for the maternal genetic effects, there was a high correlation between the intercept and the linear coefficient (0.952) and a negative correlation with quadratic components $(-0.478)$.

According to these results, $97.5 \%$ of the genetic variation of the growth curve in this first stage of the lamb's life is explained by the first 3 eigenvalues $\left(\lambda_{i}\right)$. However, the intercept $\left(\lambda_{1}\right)$ and the linear coefficient $\left(\lambda_{2}\right)$ accounted for most of the variance (64.3 and $29.7 \%$ respectively). According to Kirkpatrick et al. (1990), if selection favors $\lambda_{1}$ there will be an important response in BW during the course of the first 3 mo of age, the eigenvector associated with this eigenvalue is known as the vector of size. In contrast, the genetic variance explained by $\lambda_{2}$ is 2.16 lower than $\lambda_{1}$, if the selection is practiced on the associated eigenvector of this second eigenvalue, there will be some change in the growth curve due to the high level of variability.

Figure 2 shows changes in variance components across ages estimated with model Y3332B. Total phenotypic variance and individual permanent environmental effect increase with age. Maternal permanent environmental effect $\left(c^{2}\right)$ was very important during the first $45 \mathrm{~d}$ of age, but falls to only $3.3 \%$ at $75 \mathrm{~d}$. Genetic variance of 

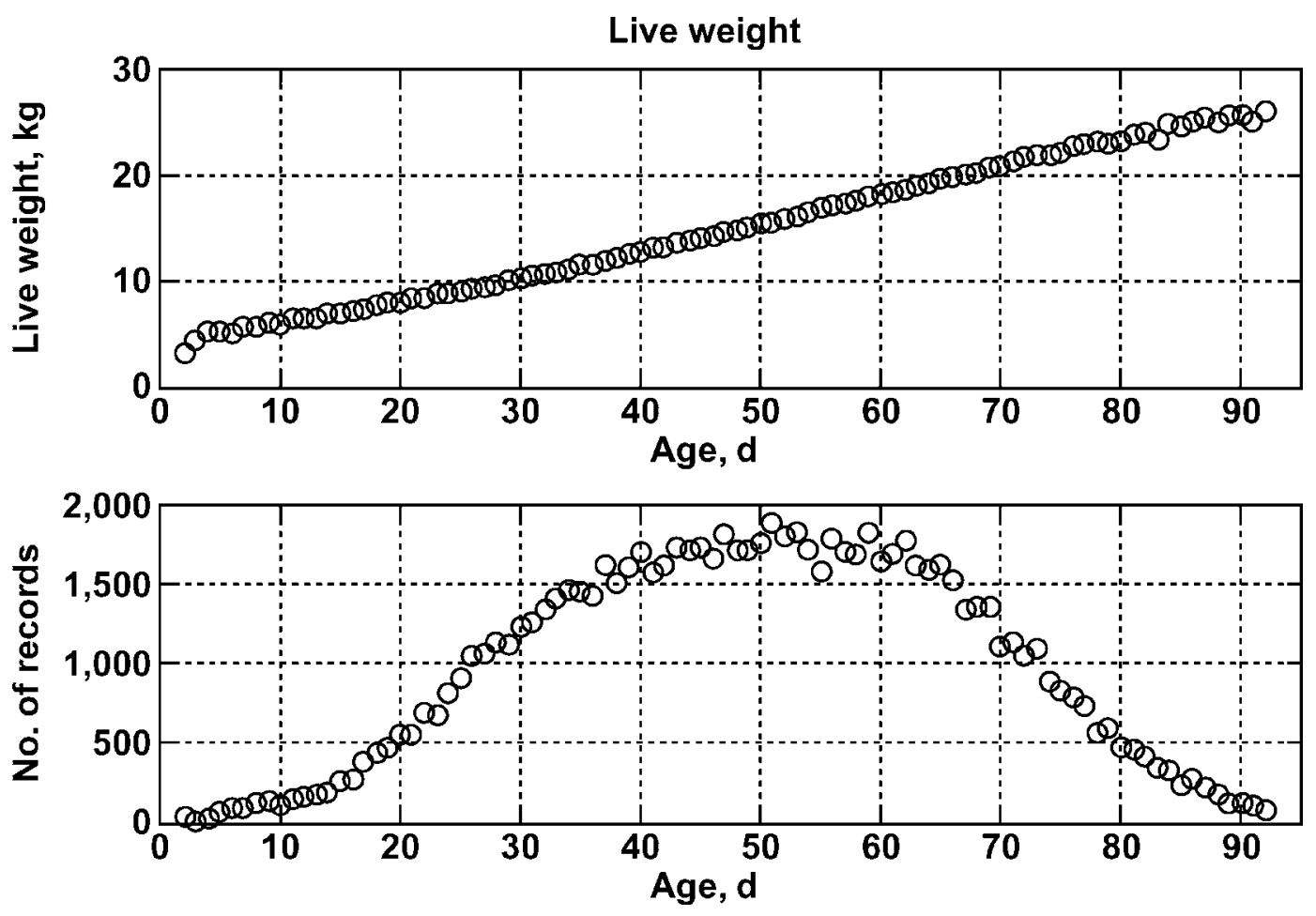

Figure 1. Number of observations and BW means during the first 3 mo of age in Spanish Merino sheep.

direct $\left(\sigma_{a}^{2}\right)$ and maternal $\left(\sigma_{m}^{2}\right)$ effects showed the same pattern through the first $45 \mathrm{~d}$; after that age the relative importance of $\sigma_{a}^{2}$ increases much faster. In contrast the covariance between both genetic effects $\left(\sigma_{a m}\right)$ decreases at the same time the animal's age increases. Heritability estimates for direct $\left(h_{a}^{2}\right)$ and maternal $\left(h_{m}^{2}\right)$ effects show opposite responses. Relative importance of $h_{m}^{2}$ increases until $45 \mathrm{~d}$, whereas $h_{a}^{2}$ falls during the same period. The correlations between direct and maternal genetic effects $\left(r_{a m}\right)$ had negative values throughout the whole period, but the absolute value was greater during the first 45 d of age.

Figure 3 shows the correlation between direct and maternal genetic effects for each age. The correlations were negative for all pairs of age considered, showing the same tendency observed in Figure 2, with their absolute values greater at ages below $45 \mathrm{~d}$.
Correlations between direct $\left(r_{a}\right)$ and maternal $\left(r_{m}\right)$ genetic effects of BW recorded through the whole age trajectory studied are shown in Figure 4. All correlations are positive, for any pair of ages considered. Correlation between adjacent or near ages are greater than 0.90 for both genetic effects. However, correlations were lower in the first $45 \mathrm{~d}$ due to the antagonism between direct and maternal genetic effects in that period of growth (see Figures 2 and 3). After $45 \mathrm{~d}$ of age all correlations are close to 1 for both effects. Correlations between individual permanent environment effect and for maternal permanent environment effect show similar patterns to those described above (Figure 5).

\section{BV Estimated from Official BLUP and RRM Comparison}

Table 4 shows a comparison between the BV estimated with RRM $\left(\mathrm{RBV}_{a}\right.$ and $\mathrm{RBV}_{m}$ here and in the next para-

Table 3. Covariance matrix of random regression coefficients ${ }^{1}$ for direct genetic effects, maternal effects, and their covariance and eigenvalues $\left(\lambda_{i}\right)$ obtained with the best fit model (3332B) for growth of Merino lambs during the first 3 mo after birth

\begin{tabular}{|c|c|c|c|c|c|c|c|}
\hline Item & $\alpha_{\mathrm{D}}^{1}$ & $\beta_{\mathrm{D} 1}$ & $\beta_{\mathrm{D} 2}$ & $\alpha_{\mathrm{M}}$ & $\beta_{\mathrm{M} 1}$ & $\beta_{\mathrm{M} 2}$ & $\lambda_{i}(\%)$ \\
\hline$\alpha_{\mathrm{D}}$ & 2.0100 & & & & & & 64.3 \\
\hline$\beta_{\mathrm{D} 1}$ & 0.9281 & 0.5761 & & & & & 29.7 \\
\hline$\beta_{\mathrm{D} 2}$ & 0.1304 & 0.1154 & 0.0986 & & & & 3.5 \\
\hline$\alpha_{\mathrm{M} 2}$ & -0.4956 & -0.1266 & 0.1113 & 1.2160 & & & 2.0 \\
\hline$\beta_{\mathrm{M} 1}$ & -0.2363 & -0.1072 & 0.0373 & 0.5223 & 0.2477 & & 0.3 \\
\hline$\beta_{\mathrm{M} 2}$ & -0.0388 & -0.0470 & -0.0757 & -0.1500 & -0.0521 & 0.0811 & 0.2 \\
\hline
\end{tabular}

\footnotetext{
${ }^{1}$ The meaning of $\alpha_{\mathrm{D}}, \beta_{\mathrm{D} 1}, \beta_{\mathrm{D} 2}$ and $\alpha_{\mathrm{M}}, \beta_{\mathrm{M} 1}, \beta_{\mathrm{M} 2}$ are the intercept, linear, and quadratic regression coefficient for genetic direct (D) and maternal (M) effects, from the random regression model.
} 

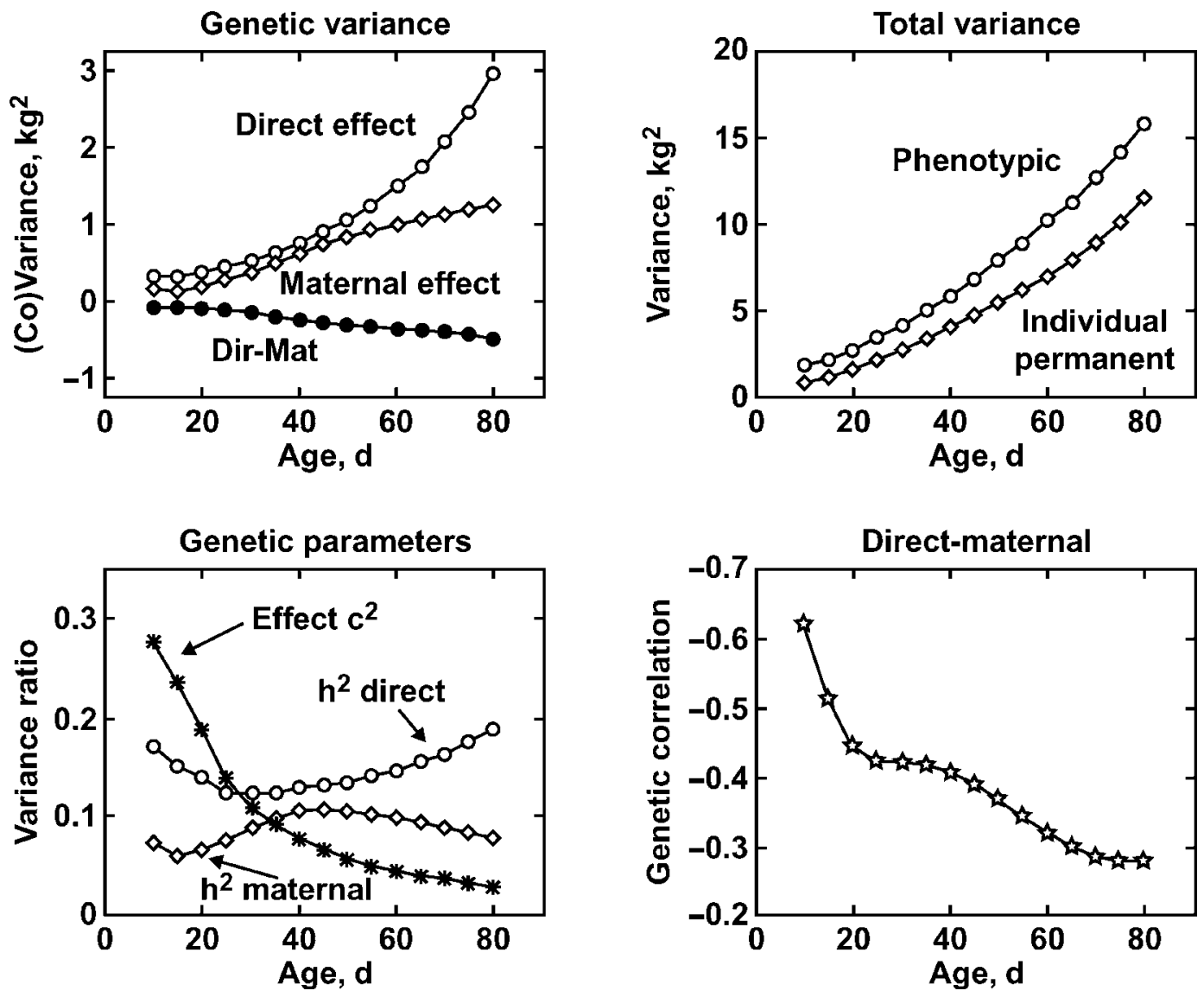

Figure 2. Evolution of the genetic variances and other genetic parameters in the first 3 mo of age in Spanish Merino sheep.

graphs the subscripts $a$ and $m$ mean direct and genetic maternal effects respectively), and the intercepts of these random regression equations $\left(\mathrm{ALPHA}_{a}\right.$ and $\mathrm{ALPHA}_{m}$ ), with the current and official BLUP estimates $\left(\mathrm{CBV}_{a}\right.$ and $\mathrm{CBV}_{m}$ ) used by SMBA. Percentage of concordance within

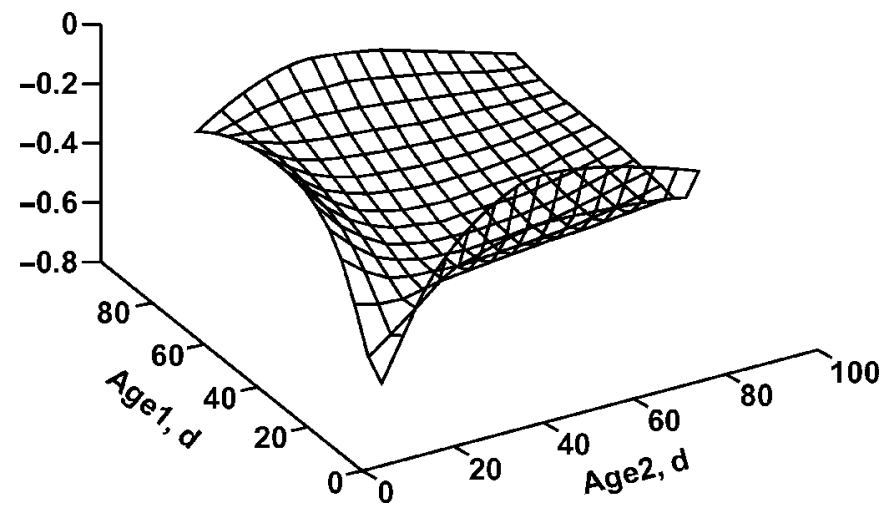

Figure 3. Genetic correlation between genetic direct and maternal effects at different ages during the first 3 mo of age in Spanish Merino sheep. For any pair of ages considered, Age1 is the age of the first weight, and Age2 is the age of the second weight. the best 500 animals selected by $\mathrm{RBV}_{a}$ and $\mathrm{RBV}_{m}$ are also given in this table.

Finally, the frequency distributions of BV estimated for direct and maternal effects of the components of a quadratic model (model Y3332B), for 45,941 Merino lambs are shown in Figure 6. All parameters are represented with the same scale.

\section{DISCUSSION}

During the last $20 \mathrm{yr}$, an effective selection program has been carried out (Valera et al., 2002) on Spanish Merino sheep with an improved growth capacity and is now greater than in other sheep populations oriented toward wool production or dual purpose (Cloete et al., 2001; Duguma et al., 2002).

Most references to genetic parameters of preweaning and postweaning (fattening) growth are restricted to BW at some fixed age-adjusted linked to commercial slaughter age. Heritability estimates obtained in this work for all points during the first 3 mo of age are within the range of values reported in a recent review (Safari and Fogarty, 2003) both for direct and maternal effects. Neser et al. (2000) and Duguma et al. (2002) have published higher estimates for these parameters for Merino under South African conditions. However, the estimates 


\section{Genetic correlation maternal effect}

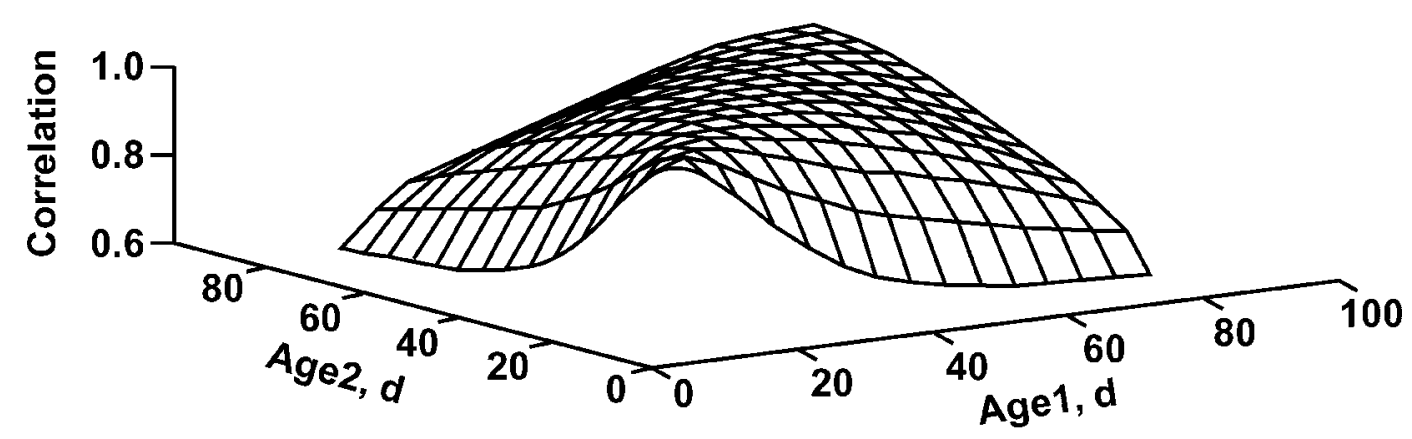

Genetic correlation maternal effect

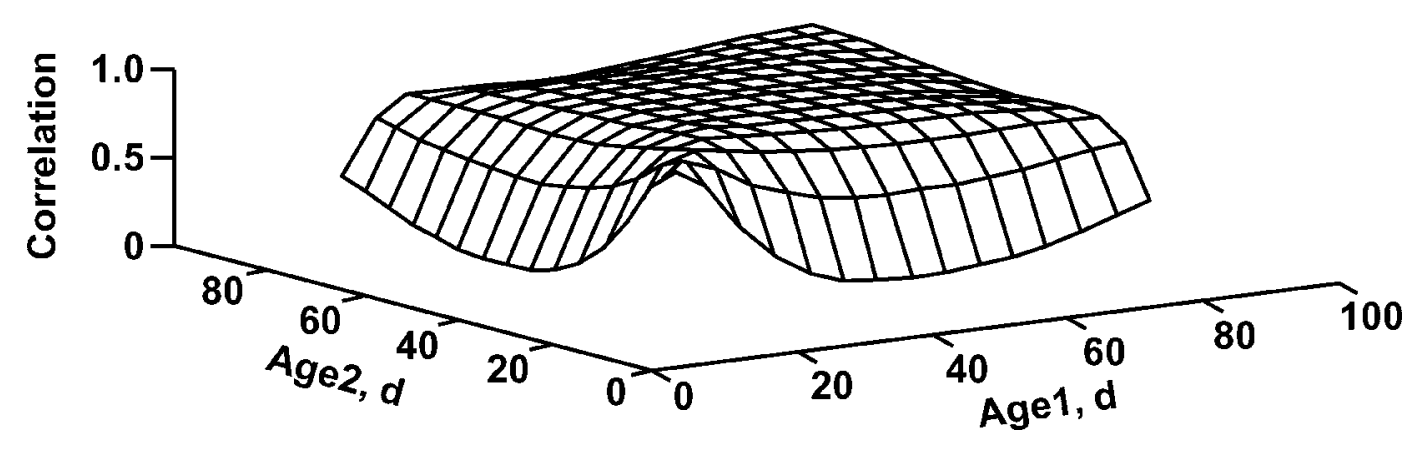

Figure 4. Genetic correlation for genetic direct and maternal effect for BW at different ages in Spanish Merino sheep. For any pair of ages considered, Age1 is the age of the first weight, and Age2 is the age of the second weight.

of these latter 2 articles were based on smaller samples with poor pedigree structure and did not use random regression methods. Despite the practical interest of BW at only a few specific ages, this trait is a continuous function of age. Therefore, if weight is recorded repeatedly along the life of the animal, it would be more useful to discuss the course of heritability along the age trajectory.

The trajectory of genetic (co)variance and the heritability estimates of BW obtained in this work show the same form, but not the same values, as those published by Lewis and Brotherstone (2002) and Fischer et al. (2004) using random regression models in Suffolk and Poll Dorset breeds, respectively. However, a null covariance between direct and maternal genetic effects was assumed in these last 2 studies. This could generate biased estimates not only for excluding a possible covariance between both genetic components, but also for not considering changes of this covariance with age.

Published estimates of correlations between direct and maternal genetic effects $\left(r_{a m}\right)$ cover a wide range of values. For example, Maria et al. (1993) reported $r_{a m}=$ -0.97 for weaning weight in Romanov, whereas Saatci et al. (1997) found $r_{a m}=0.99$ for preweaning weights in Welsh Mountain. The recent review published by Safari and Fogarty (2003) presented 71 estimates of $r_{a m}$ for BW at different ages in sheep, from which $69 \%$ were negative. The biological interpretation of these extreme values is difficult and has generated much discussion. Often inconsistencies among published results come from differences in the structure of the data and pedigree information used, as Maniatis and Pollott (2003) showed and confirmed with the recently published paper by Safari et al. (2005). We can conclude that in this Spanish Merino sheep population there is an antagonism between direct and maternal genetic effects for weights measured during the first 3 mo of life. In our case the data structure used, with a large data set and a complete pedigree available (50\% of lambs sires, for example, appear also as maternal grand sires), can be considered suitable for this estimation. Sierra et al. (1998) and Menéndez-Buxadera et al. (2003b) found similar results with Merino sheep in Spain, but in these studies only a few fixed ages were presented.

The trajectory of this genetic antagonism follows a second order equation with greater values (more negative) during the first $45 \mathrm{~d}$ of age (see Figures 2 and 3). A similar tendency was observed by Maniatis and Pollott (2002) using univariate models. These changes in the covariance between direct and maternal genetic effects during the course of the first 3 mo of age make it difficult to interpret the evolution of each parameter. In that sense, a principal component analysis carried out with the random regression coefficient matrix, allowed us to identify the first 2 eigenvalues, which explain $94 \%$ of the genetic variation of the shape of the growth curves 


\section{Individual permanent environmental effect}

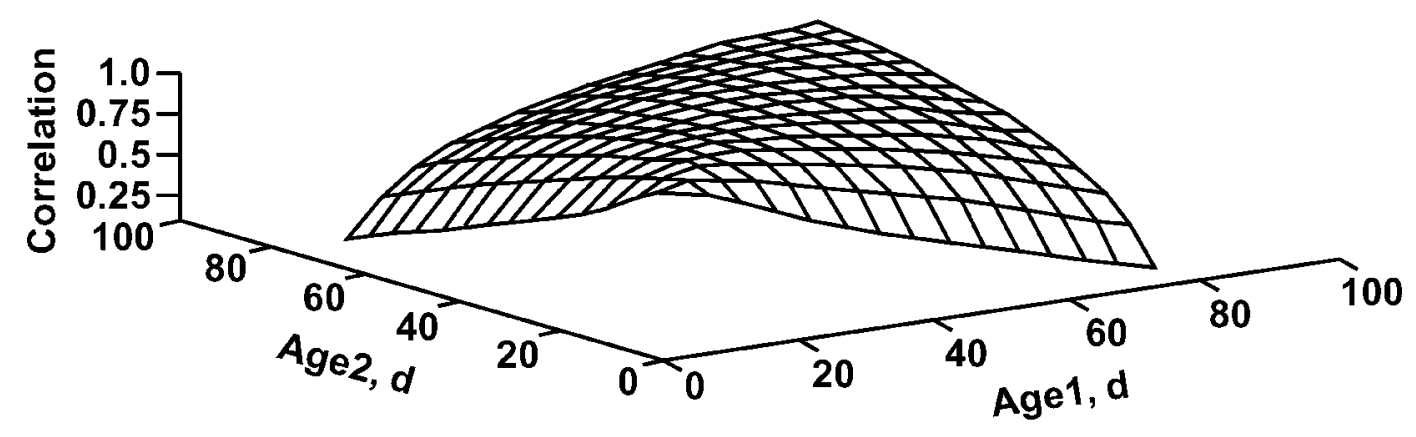

Maternal permanent environmental effect

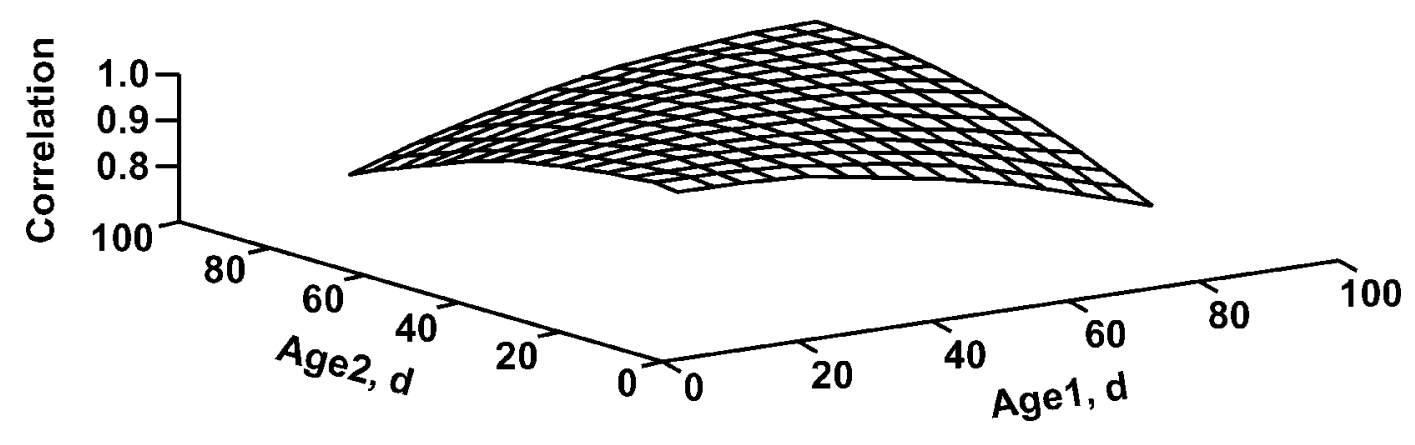

Figure 5. Correlation between BW at different ages in Spanish Merino sheep for individual and maternal permanent environmental effects. For any pair of ages considered, Age1 is the age of the first weight, and Age2 is the age of the second weight.

during the first $3 \mathrm{mo}$ of age. The eigenvectors associated with these eigenvalues and the corresponding Legendre polynomials can be manipulated to obtain the eigenfunctions, which may be very useful for further genetic analyses of growth curves, in the same way that was done by Druet et al. $(2003,2005)$ in dairy cattle. These eigenfunc-

Table 4. Simple correlations between breeding value for direct (d) and maternal (m) effects of Spanish Merino for BW at $75 \mathrm{~d}$ of age estimated with random regression models $(\mathrm{RRM})^{1}$ and the intercepts of these random regression equations, with current BLUP $^{2}$ predictions obtained using BW adjusted previously to a 75-d fixed age

\begin{tabular}{lcc}
\hline \hline Item & CBVd & CBVm \\
\hline RVGd & 0.870 & \\
RVGm & & 0.749 \\
\% of animals coincident & & \\
ALPHAd & 57.4 & 40.2 \\
ALPHAm & 0.878 & 0.769 \\
\% coincident* & 60.2 & 43.0 \\
\hline
\end{tabular}

${ }^{1} \mathrm{RVGd}$ and RVGm are the breeding value of the animals estimated by the best RRM model at 75 d of age exactly. ALPHAd and ALPHAm are the intercept of the genetic random regression.

${ }^{2} \mathrm{CBVd}$ and $\mathrm{CBVm}$ are the breeding value of the animals estimated by an animal model following the classical procedure used by the SMBA.

${ }^{3}$ Percentage of animals coinciding within the best 500 animals selected by their RVGd and RVGm values. tions are uncorrelated by definition; therefore, they may contribute to a better understanding of the antagonism between direct and maternal genetic effects, but more research is needed on this aspect. More recently Kirkpatrick and Meyer (2004), Meyer and Kirkpatrick (2005a,b), and Meyer (2006) presented an excellent review on the statistical background and practical interest on the use of eigenfunctions to analyze data that can be represented as points on a curve.

Our results showed that a quadratic equation for direct and maternal genetic effects is the best order of fit for growth during the first 3 mo of life of Merino lambs. This order of fit $(\mathrm{k}=3)$ was found to be adequate to describe these genetic effects during the preweaning growth both for lambs (Fischer et al., 2004) and for calves (Meyer, 2001; Nobre et al., 2003). Therefore, using BW adjusted previously at fixed ages assuming a linear growth (as it is usually done in this breeding program by SMBA) may generate a bias. To better understand this bias, correlations were estimated between BV for direct and maternal effects for BW exactly at $75 \mathrm{~d}$ of age, for all lambs represented in this data set. The simple correlations between those BV estimated with RRM $\left(\mathrm{RBV}_{\mathrm{a}}\right.$ and $\left.\mathrm{RBV}_{m}\right)$, with the current and official BLUP estimations $\left(\mathrm{CBV}_{\mathrm{a}}\right.$ and $\left.\mathrm{CBV}_{m}\right)$ are generally positive but moderate; however, the results with the intercepts $\left(\mathrm{ALPHA}_{\mathrm{a}}\right.$ and $\mathrm{ALPHA}_{m}$ ) were slightly greater (Table 4). These correlations mean that the expected selection re- 
Genetic direct effect
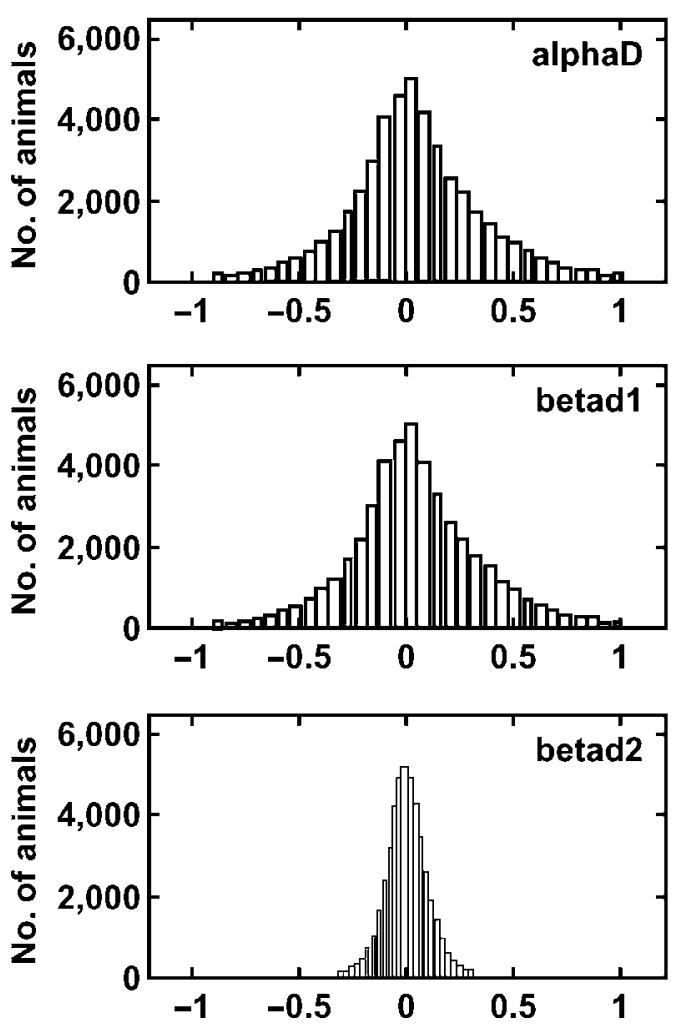

Maternal genetic effect
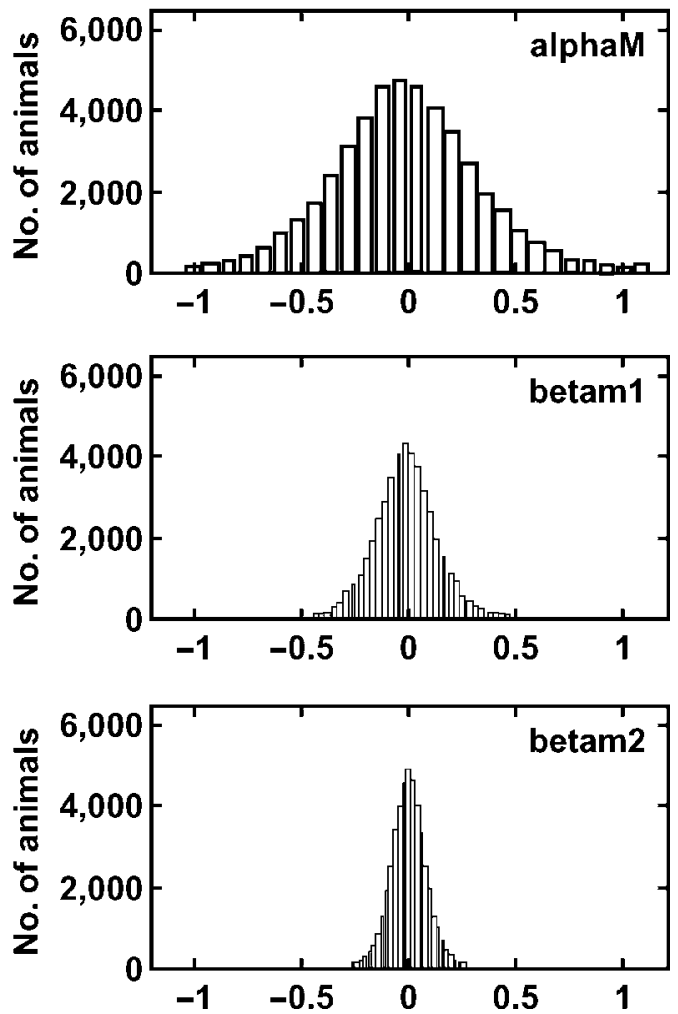

Figure 6. Variability in breeding value in Spanish Merino sheep for genetic direct and maternal effects estimated for the genetic components of the random regression models. The meaning of alpha, beta1, and beta2 are the intercept, linear, and quadratic regression coefficients for each animal for direct (D) and maternal (M) effects, respectively, estimated by using the 3332B random regression model.

sponse, based on BV estimated by the current BLUP or by RRM, will be positive but not optimal when the ages of the animals are distant. These correlations decrease as intervals between ages increase. So, the direct selection based on the weight at one age creates an indirect response in the weight at the second age. That indirect response will be greater as the difference between the 2 ages shrinks. It is necessary to take into consideration the fact that BW at $75 \mathrm{~d}$ of age is highly correlated with BW at very close ages, however the results with earlier ages (first $45 \mathrm{~d}$ of age) will be lower (see Figure 3) due to a more pronounced antagonism between direct and maternal genetic effects. This is the same relationship pattern presented by Lewis and Brotherstone (2002) and Fischer et al. (2004).

The results presented in Table 4 also show that animals selected with either procedure are not the identical. For example, from the best 500 animals selected according to their $\mathrm{RBV}_{a}$ and $\mathrm{RBV}_{m}$ values, only 287 (57.4\%) and $201(40.2 \%)$ would be selected for their official $\mathrm{CBV}_{\mathrm{a}}$ and $\mathrm{CBV}_{m}$ values, respectively. These proportions or percentages of selected animals that agree in both methods increase when selection is based on $\mathrm{ALPHA}_{a}$ and $\mathrm{ALPHA}_{m}$ values $\left(60.2 \%\right.$ for $\mathrm{CBV}_{a}$ and $43 \%$ for $\left.\mathrm{CBV}_{m}\right)$. This means that BV estimated by the current methods from SMBA are more highly correlated with the general average breeding value than with BV exactly estimated by RRM at $75 \mathrm{~d}$, which also include genetic differences in the form of the growth curve. This low level of accuracy for ranking the animals according to its $\mathrm{BV}$ is the more serious problem related to the official procedure.

Finally, this study has identified a large amount of genetic variation that can be used to improve the breed (Figure 6). For a better understanding of these figures it should be highlighted that the average BW of all data sets is $16.3 \mathrm{~kg}$ at an average age of $49.8 \mathrm{~d}$. It can be observed that the direct genetic effect shows more variability than the maternal effect, both for the ALPHA component and for the linear component of the genetic regression equation. $\mathrm{ALPHA}_{a}$ values ranged between -1.5 and $+1.9 \mathrm{~kg}$, whereas for $\mathrm{ALPHA}_{\mathrm{m}}$ varied between -1.0 and $+1.1 \mathrm{~kg}$. These represent 20.9 and $12.9 \%$ of the mean BW, respectively. On the other hand, the variation in linear terms was twice as large for direct genetic effects (from -0.87 to $+0.99 \mathrm{~kg}$ ) than for maternal effects (from -0.4 to $+0.5 \mathrm{~kg}$ ). Quadratic terms were similar for both types of effects.

These results indicate that there is a large potential for selection and breed improvement in this population of Merino sheep and that official methods making prior adjustments to a fixed age should be revised, particularly 
when a linear relationship between weight and age is assumed.

In conclusion, the current methods applied by SMBA to estimate BV of the animals are less informative and less accurate than predictions from RRM. This suggests that the ranking of animals can change along the trajectory of the BW during the first 3 mo of age. Accordingly, from the results of this research the longitudinal approach must be recommended because it provides more information for breeding programs of the Spanish Merino. We have also found that there is an antagonism between direct and maternal genetic effects throughout the course of the growth curve during the first 3 mo of age, but this antagonism decreases with age.

Substantive genetic variation has been identified not only in the general level of breeding value but also in the shape of the growth curve. The estimation of these parameters will provide more information to breeders to select animals that fulfill the market requirements on slaughter age and weight.

\section{LITERATURE CITED}

Cloete, S. W. P., J. C. Greeff, and R. P. Lewer. 2001. Environmental and genetic aspects of survival and early BW in Western Australian Merino sheep. S. Afr. J. Anim. Sci. 31:123-130.

Druet, T., F. Jaffrézic, D. Boichard, and V. Ducrocq. 2003. Modeling Lactation curves and estimation of genetic parameters for first lactation test-day records of French Holstein cows. J. Dairy Sci. 86:2480-2490.

Druet, T., F. Jaffrézic, and V. Ducrocq. 2005. Estimation of genetic parameters for test day records of dairy traits in the first three lactations. Genet. Sel. Evol. 37:257-271.

Duguma, G., S. J. Schoeman, S. W. P. Cloete, and G. F. Jordaan. 2002. Genetic parameter estimates of early growth traits in the tygerhoek Merino flock. S. Afr. J. Anim. Sci. 32:66-75.

Fischer, T. M., J. H. J. van der Werf, R. G. Banks, and A. J. Ball. 2004. Description of lamb growth using random regression. Livest. Prod. Sci. 89:175-185.

Foulley, J. L., and C. Robert-Granié. 2002. Basic tools for the statistical analysis of longitudinal data via mixed model. Special workshop associated with the 7th World Congr. Genet. Appl. Livest. Prod., Montpellier, France. pp 159.

Gilmour, A. R., B. R. Cullis, S. J. Welham, and R. Thompson. 2000. ASREML Reference Manual. NSW Agric. Biom. Bull. NSW Agriculture, Locked Bag, Orange, NSW 2800, Australia.

Jamrozik, J., and L. R. Schaeffer. 1997. Estimates of genetic parameters for a test day model with random regression for production of first lactation. J. Dairy Sci. 80:762-770.

Kirkpatrick, M., D. Lofsvold, and M. Bulmer. 1990. Analysis of the inheritance, selection and evolution of growth trajectories. Genetics 124:979-993.

Kirkpatrick, M., and K. Meyer. 2004. Simplified analysis of complex phenotypes: Direct estimation of genetic principal components. Genetics 168:2295-2306.

Lewis, R. W., and S. Brotherstone. 2002. A genetic evaluation of growth in sheep using random regression techniques. Anim. Sci. 74:63-70.
Maniatis, N., and G. E. Pollott. 2002. Maternal effects on weight and ultrasonically measured traits of lambs in a small closed Suffolk flock. Small Rumin. Res. 45:235-246.

Maniatis, N., and G. E. Pollott. 2003. The impact of data structure on genetic (co)variance components of early growth in sheep, estimated using an animal model with maternal effects. J. Anim. Sci. 81:101-108.

Maria, G. A., K. G. Boldman, and L. D. Van Vleck. 1993. Estimates of variances due to direct and maternal effects for growth traits of Romanov sheep. J. Anim. Sci. 71:845-849.

Menéndez-Buxadera, A., J. M. Serradilla, M. Valera, and A. Molina. 2003a. Estimación de Parámetros Genéticos del Peso Vivo en los primeros 75 días de edad en ovino Merino Español. Pages 519-521 in Proc. X Jornadas sobre Producción Animal, Zaragoza, Spain.

Menéndez-Buxadera, A., M. Valera, J. M. Serradilla, and A. Molina. 2003b. Factores ambientales que afectan a la curva de crecimiento de corderos de la raza Merina. Pages 555-557 in Proc. X Jornadas sobre Producción Animal, Zaragoza, Spain.

Meyer, K. 1997. Estimates of genetic parameters for weaning weight of beef cattle accounting for direct-maternal environmental covariances. Livest. Prod. Sci. 52:187-199.

Meyer, K. 2001. Estimates of direct and maternal covariance functions for growth of Australian beef calves from birth to weaning. Genet. Sel. Evol. 33:487-514.

Meyer, K. 2006. To have your steak and eat it: Genetic principal component analysis for beef cattle data. Comm. No. 25 in Proc. 8th World Congr. Genet. Appl. Livest. Prod., Belo Horizonte, Brazil.

Meyer, K., and M. Kirkpatrick. 2005a. Restricted maximum likelihood estimation of genetic principal components and smoothed covariance matrices. Genet. Sel. Evol. 37:257-271.

Meyer, K., and M. Kirkpatrick. 2005b. Up hill, down dale: Quantitative genetics of curvaceous traits. Philos. Trans. R. Soc. 360:14431455 .

Neser, F. W. C., G. J. Erasmus, and J. B. van Wyk. 2000. Genetic studies on South African mutton Merino: Growth traits. S. Afr. J. Anim. Sci. 30:172-177.

Nobre, P. R. C., I. Misztal, S. Tsuruta, J. K. Bertrand, L. O. C. Silva, and P. S. Lopes. 2003. Analysis of growth curves of Nellore cattle by multiple-trait and random regression models. J. Anim. Sci. 81:918-926.

Saatci, M., A. P. Dewi, and Z. Ululas. 1997. Variance due to direct and maternal effect for weight of Welsh Mountain lambs based on embryos transfer data. Page 176 in Proc. Br. Soc. Anim. Sci., Edinburgh, UK. Appleby, ed. Br. Soc. Anim. Sci., Midlothian, UK.

Safari, A., and N. M. Fogarty. 2003. Genetic parameters for sheep production traits: Estimates from the literature. Technical Bulletin No. 49, NSW Agriculture, Orange, Australia.

Safari, E., N. M. Fogarty, and A. R. Gilmour. 2005. A review of genetic parameter estimates for wool growth, meat and reproduction traits in sheep. Livest. Prod. Sci. 92:271-289.

Sierra, A. C., J. V. Delgado, A. Molina, C. Barba, F. Barajas, and A. Rodero. 1998. Genetic parameters of weight and growth traits in the Spanish Merino Sheep. Pages 143-145 in Proc. 5th World Merino Conference Breeding \& Marketing for the 21st Century, Christchurch, New Zealand. World Fed. of Merino Breeders, New Zealand.

Valera, M., M. Juárez, P. Azor, F. Barajas, A. Rodero, and A. Molina. 2002. A genetic study of the potential of growth of lambs in the native Spanish Merino Sheep. Page 80 in Proc. 6th World Merino Conference "Natural Fibre and Food for the World", Budapest, Hungary. Hungarian Sheep Breeder's Assoc. 